\title{
Effect of anxiety and depression on blood pressure: 11-year longitudinal population study
}

\author{
Bjørn Hildrum, Arnstein Mykletun, Jostein Holmen and Alv A. Dah
}

\section{Background}

The long-term effect of anxiety and depression on blood pressure is unclear.

\begin{abstract}
Aims
To examine the prospective association of anxiety and depression with change in blood pressure in a general population.
\end{abstract}

\section{Method}

Data on 36530 men and women aged 20-78 years participating in the Nord-Trøndelag Health Study (HUNT) in Norway in 1984-86 were re-examined 11 years later.

\section{Results}

A high symptom level of anxiety and depression at baseline predicted low systolic blood pressure ( $<10$ th percentile) at follow-up $(\mathrm{OR}=1.30,95 \% \mathrm{Cl}$ 1.08-1.57) when those with low systolic blood pressure at baseline were excluded. Change in symptom level of anxiety and depression between baseline and follow-up was inversely associated with change in systolic blood pressure. For diastolic blood pressure, the findings were weaker or non-significant.

\section{Conclusions}

Symptoms of anxiety and depression predicted lower blood pressure 11 years later.

\section{Declaration of interest}

B.H. has received financial support from $\mathrm{H}$. Lundbeck. Funding detailed in Acknowledgements.
The hypothesis that psychological factors influence blood pressure is at least 100 years old. Descriptions of 'polycythemia hypertonica' and of 'hypertension'2 have insinuated that there might be a history of emotional stress behind the origin of these terms. Whether symptoms of anxiety and depression contribute to the development of hypertension has been addressed in several studies, but with inconclusive results. A few studies using change in mean blood pressure as outcome ${ }^{3-7}$ found mostly no effect.

We recently reported an inverse cross-sectional association of anxiety and depression with blood pressure in a large, community-based population. ${ }^{8}$ We designed the present study to estimate prospectively the effect of anxiety and depression on change in blood pressure 11 years later within the same population.

\section{Method}

\section{Participants}

In the Nord-Trøndelag Health Study (HUNT study), all inhabitants in the county of Nord-Trøndelag aged 20 years and older were invited to participate in a general health study that was conducted twice: in 1984-86 (HUNT-1) and 1995-97 (HUNT-2). Data were obtained from physical examinations, blood samples and questionnaires that covered demographic characteristics, somatic illnesses, somatic and mental symptoms, medication, lifestyle and health-related behaviour., ${ }^{9,10}$

Among participants aged 20-89 years in the two surveys, 60143 of the HUNT-1 participants and 60799 of the HUNT-2 participants ${ }^{8}$ had valid data on anxiety/depression and blood pressure. These two comparable cross-sectional samples were used for the purpose of cross-validation. The inclusion criteria for our 11year longitudinal study were valid data on anxiety, depression and blood pressure in both surveys. Of the 60143 HUNT-1 participants, 57471 were $20-78$ years old; 9708 of these individuals died or moved out of the county during follow-up. Of the remaining 47763 individuals, $76.5 \%$ participated in HUNT-2 with valid data, giving a study population of 36530 participants aged 20-78 years at baseline (31-89 years old at follow-up). Compared with participants $(n=36530)$, those who did not complete the study ( $n=11233$ ) among eligible individuals were older (51 v. 44 years) and more often men (49.7 v. 47.4\%), had higher mean blood pressure $(141 / 86$ v. $131 / 83 \mathrm{mmHg})$ and higher symptom scores of anxiety/depression (mean $z$-score $=0.07$ (s.d.=1.08) v. -0.02 (s.d.=0.97); $P<0.001$ for all comparisons). However, there was no interaction between age or gender and the association of interest. ${ }^{8}$ Consequently, we did not expect non-completers to bias our results. The Norwegian Data Inspectorate and The Regional Committee for Ethics in Medical research approved the study.

\section{Measures of anxiety and depression}

Twelve questions on anxiety and depression were included in the baseline questionnaire, consisting of a one-dimensional anxiety and depression symptom index (the ADI-12 Index) that correlated strongly $(r=0.82)$ with the Hopkins Symptoms Checklist25 in a subsample re-examined 2 years after baseline screening. ${ }^{11}$ The test-retest correlation over 2 years for the ADI-12 Index was considered good $(r=0.66) .{ }^{11}$ Five of the ADI-12 items corresponded with ICD-10 12 criteria of depressive episode (code F32), and three items corresponded with ICD-10 criteria of generalised anxiety disorder (code F41.1). Two items were related to feelings of being under pressure, one to the use of tranquillisers or sleeping pills, and one to being more aware of responsibilities than others.

The Hospital Anxiety and Depression Scale (HADS) was employed at follow-up. ${ }^{13}$ The HADS is a self-report questionnaire comprising 14 four-point Likert-scaled items, 7 for anxiety and 7 for depression. ${ }^{14}$ Cross-sectional analyses in the same population indicated that HADS-defined anxiety and depression, respectively, were similarly associated with blood pressure. ${ }^{8}$ Consequently, onedimensional measures for symptoms of anxiety and depression were used at both baseline and follow-up, and $z$-scores of both measures were used to compare mean symptom levels.

Symptom load of anxiety and depression at baseline was used both as a continuous measure and categorically as a dichotomy 
with cut-offs at the 90th percentile. Change in symptom load from baseline to follow-up (difference in $z$-scores between baseline and follow-up) was used as a continuous measure and categorically as 10 -percentile groups $(0-10,11-20, \ldots$ 91-100th percentile). Percentiles above the median indicated a relative increase in symptom load and below the median indicated a relative decrease.

\section{Blood pressure measurements}

Specially trained nurses measured blood pressure in seated participants after $4 \mathrm{~min}$ (baseline) or $2 \mathrm{~min}$ (follow-up), with the cuff placed on the right upper arm and with the arm resting on a table. At baseline, blood pressure was measured using calibrated mercury manometers with standard cuff size. The first pulse sound (Korotkoff's phase I) was registered as systolic blood pressure and the level at which the pulse disappeared (phase V) as diastolic blood pressure. The measurements were repeated after $2 \mathrm{~min}$ and the second reading was used in this study. At follow-up, blood pressure was measured with a Dinamap 845XT (Criticon, Florida, USA) based on oscillometry. Cuff size was adjusted after measuring the arm circumference. Blood pressure was measured automatically three times at $1 \mathrm{~min}$ intervals. The mean of the second and third reading was used in this study.

\section{Outcome measures}

The outcome measures were change in mean systolic or diastolic blood pressure (the participant's blood pressure at follow-up minus blood pressure at baseline), and systolic or diastolic hypotension (defined as age- and gender-stratified blood pressure $\leqslant 10$ th percentile) or hypertension ( $\geqslant 90$ th percentile) at followup. Reasons for using age- and gender-stratified percentiles rather than fixed blood pressure values have been described previously. ${ }^{8}$

\section{Statistical analysis}

First, we used linear regression models to examine the association of symptom loads of anxiety and depression at baseline and change in symptom load from baseline to follow-up with change in mean systolic or diastolic blood pressure. Effects were reported as unstandardised regression coefficients $(\mathrm{B}=\mathrm{mmHg}$ per standard deviation increase in symptoms of anxiety and depression at baseline or from baseline to follow-up). Additionally, we performed gender-stratified analyses, and repeated analyses after excluding individuals taking antihypertensive or antidepressant medication. In separate analyses we examined the association between individual anxiety and depression items at baseline and change in blood pressure.

Second, we used logistic regression models to predict systolic or diastolic hypotension (defined as age- and gender-stratified blood pressure $\leqslant 10$ th percentile) at follow-up, when individuals with low systolic or diastolic blood pressure $(\leqslant 30$ th percentile) at baseline were excluded. We used separate analyses with anxiety and depression as continuous and categorical measures, as described above. For the purpose of predicting hypertension (blood pressure $\geqslant 90$ th percentile) at follow-up, we excluded individuals with high blood pressure ( $\geqslant 70$ th percentile) at baseline.

All regression models were adjusted for age (5-year categories as dummy coded variables), gender, education (three levels), and baseline systolic or diastolic blood pressure. In the fully adjusted linear models, we further included hypertension among siblings (dichotomy), angina pectoris, myocardial infarction, stroke, diabetes mellitus (never, follow-up only, or both), smoking status, use of antihypertensive medication (never, baseline only, follow-up only, or both) and body mass index (baseline and change, both continuous).
Third, we displayed graphically the unadjusted association of change in symptom load of anxiety and depression with change in blood pressure. Effects were displayed with $95 \%$ confidence intervals.

Finally, for the purpose of cross-validation, we performed cross-sectional analyses applying HUNT-1 data, aiming to replicate the associations previously reported from HUNT-2 data. ${ }^{8}$ We used logistic regression models with systolic and diastolic blood pressure (encoded in age- and gender-stratified percentiles), and anxiety and depression scores above the 90th percentile both at baseline and follow-up. Data were analysed using SPSS version 14.0 for Windows.

\section{Results}

Characteristics of the sample included for longitudinal analyses $(n=36530)$ are listed in Table 1 . Mean systolic blood pressure increased during follow-up, whereas mean diastolic blood pressure remained almost unchanged. The baseline and follow-up

\section{Table 1 Baseline and 11-year follow-up characteristics \\ of participants $(n=36530)$}

Variable

\begin{tabular}{lc} 
Age at baseline, years: mean (s.d.) & $44.3(13.8)$ \\
\hline Men, \% & 47.4 \\
\hline Education at baseline, \% & \\
$\leqslant 9$ years & 46.3 \\
$10-12$ years & 42.6 \\
$\geqslant 13$ years & 11.1
\end{tabular}

Medical history, \%

Angina pectoris

Baseline and follow-up $\quad 1.9$

Follow-up only $\quad 6.0$

Myocardial infarction

Baseline and follow-up $\quad 0.9$

Follow-up only $\quad 3.9$

Stroke

Baseline and follow-up $\quad 0.5$

Follow-up only 2.2

Diabetes mellitus

Baseline and follow-up $\quad 1.0$

Follow-up only 3.4

On antihypertensive medications, \%

Baseline only

Both

8.4

5.1

On antidepressant medications, ${ }^{a} \%$

Follow-up only

3.3

Hypertension among siblings, \% Baseline only

smokers, \%

Baseline only 12.3

Follow-up only

Both

Blood pressure, mmHg: mean (s.d.)

Baseline

Systolic

Diastolic

Change from baseline to follow-up Systolic

Diastolic

Body mass index, $\mathrm{kg} / \mathrm{m}^{2}$ : mean (s.d.) 
measurements correlated strongly for both systolic ( $r=0.63$, $P<0.001)$ and diastolic $(r=0.49, P<0.001)$ blood pressure and for anxiety and depression symptom scores $(r=0.46, P<0.001)$. The changes in anxiety and depression scores, and in systolic and diastolic blood pressure during follow-up, were normally (bell-shaped) distributed.

\section{Effect of anxiety and depression at baseline}

Baseline anxiety and depression predicted a relative decrease in blood pressure. Baseline level of anxiety and depression was associated with a decrease in mean systolic $(B=-0.32$, $P<0.001)$ and diastolic $(B=-0.17, P=0.002)$ blood pressure. The associations were similar in men and women, and further adjustment for the other covariates listed in Table 1 did not change the results (data not shown). Excluding individuals on antidepressant medication did not reduce the decrease in systolic $(\mathrm{B}=-0.32, P<0.001)$ and diastolic $(\mathrm{B}=-0.18, P=0.001)$ blood pressure. When individuals on antihypertensive medication were excluded, the corresponding values were $\mathrm{B}=-0.41, P<0.001$ and $\mathrm{B}=-0.18, P=0.002$.

In logistic regression models where individuals with low systolic or diastolic blood pressure $(<30$ th percentile) at baseline were excluded, anxiety and depression predicted hypotension (blood pressure $<10$ th percentile) 11 years later (Table 2). Similar findings were obtained without any exclusions and when individuals below the 10th, 20th, 40th or 50th percentiles were excluded (results not shown); however, the highest odds ratios were observed when individuals with baseline systolic or diastolic blood pressure <30th percentile were excluded (Table 2). Conversely, after similar successive exclusions of individuals with high baseline blood pressure, we did not find anxiety and depression significantly associated with hypertension (blood pressure $>90$ th percentile) at follow-up, except for diastolic blood pressure when individuals with baseline diastolic blood pressure $>70$ th percentile were excluded (Table 3).

\section{Effect of change in anxiety and depression}

Change in symptom load of anxiety and depression from baseline to follow-up was inversely associated with change in mean systolic $(\mathrm{B}=-0.34, P<0.001)$ and diastolic $(\mathrm{B}=-0.12, P=0.026)$ blood pressure. In the fully adjusted models, the effect was weaker for systolic $(B=-0.27, P=0.001)$ and not statistically significant for diastolic blood pressure $(B=-0.09, P=0.105)$.

Figure 1 shows a dose-response decrease in systolic blood pressure, when change in mean blood pressure from baseline to follow-up was calculated per 10th percentile of change in symptom load of anxiety/depression from baseline to follow-up. Individuals with the greatest increase (91-100th percentile change) in symptoms of anxiety and depression had a significantly lower increase in systolic blood pressure $(8.1$ v. $10.4 \mathrm{mmHg}$, $P<0.001)$, compared with individuals with the greatest decrease $(0-10$ th percentile change) in anxiety and depression. However, this inverse association was not found for diastolic blood pressure.

\section{Effect of individual anxiety/depression items at baseline}

In separate analyses we found that most individual anxiety and depression items at baseline were associated with a decrease in mean blood pressure during follow-up (results not shown), which is in line with the main result of this paper.

\section{Supplementary cross-sectional findings}

The cross-sectional inverse association of systolic blood pressure with anxiety and depression symptom scores above the 90th percentile was equivalent at baseline and follow-up (Fig. 2), despite use of different measures for blood pressure, and anxiety and depression. Similarly, the association of diastolic blood pressure with symptoms of anxiety and depression was almost identical for the two surveys (results not shown).

\begin{tabular}{|c|c|c|c|c|c|c|}
\hline & \multicolumn{3}{|c|}{$\begin{array}{l}\text { Low systolic blood pressure } \\
(<10 \text { th percentile })^{\mathrm{b}} \text { at follow-up }\end{array}$} & \multicolumn{3}{|c|}{$\begin{array}{c}\text { Low diastolic blood pressure } \\
(<10 \text { th percentile })^{\mathrm{b}} \text { at follow-up }\end{array}$} \\
\hline & $\mathrm{OR}^{\mathrm{C}}$ & $95 \% \mathrm{Cl}$ & $P$ & $\mathrm{OR}^{\mathrm{c}}$ & $95 \% \mathrm{Cl}$ & $P$ \\
\hline \multicolumn{7}{|l|}{ Baseline anxiety/depression score } \\
\hline Continuous measure (per s.d. increase) & 1.10 & $1.04-1.17$ & 0.001 & 1.07 & $1.01-1.12$ & 0.015 \\
\hline$\geqslant 90$ th percentile & 1.30 & $1.08-1.57$ & 0.005 & 1.14 & $0.96-1.36$ & 0.129 \\
\hline
\end{tabular}

\begin{tabular}{|c|c|c|c|c|c|c|}
\hline & \multicolumn{3}{|c|}{$\begin{array}{l}\text { High systolic blood pressure } \\
\text { (>90th percentile })^{b} \text { at follow-up }\end{array}$} & \multicolumn{3}{|c|}{$\begin{array}{c}\text { High diastolic blood pressure } \\
\text { (>90th percentile })^{\mathrm{b}} \text { at follow-up }\end{array}$} \\
\hline & $\mathrm{OR}^{\mathrm{C}}$ & $95 \% \mathrm{Cl}$ & $P$ & $\mathrm{OR}^{\mathrm{c}}$ & $95 \% \mathrm{Cl}$ & $P$ \\
\hline \multirow{3}{*}{$\begin{array}{l}\text { Baseline anxiety/depression score } \\
\text { Continuous measure (per s.d. increase) } \\
\quad \geqslant 90 \text { th percentile }\end{array}$} & & & & & & \\
\hline & 0.98 & $0.92-1.04$ & 0.445 & 0.95 & $0.90-1.00$ & 0.059 \\
\hline & 0.91 & $0.75-1.11$ & 0.358 & 0.83 & $0.69-0.99$ & 0.041 \\
\hline
\end{tabular}


(a)

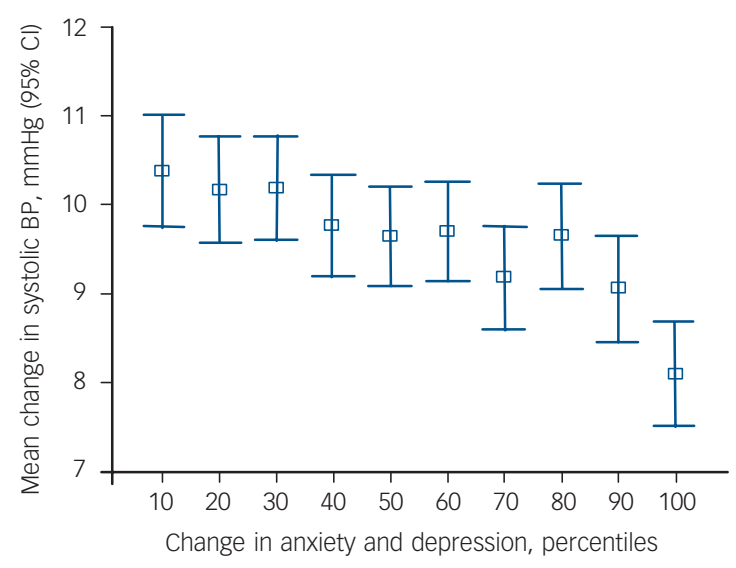

(b)

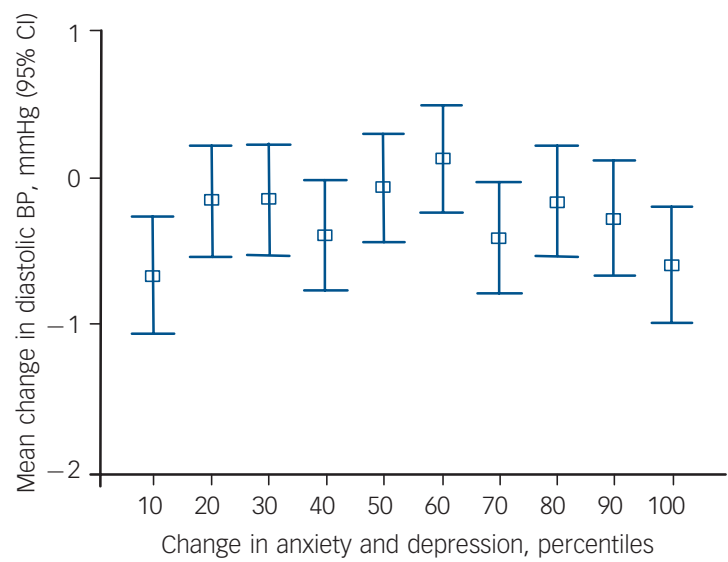

Fig. 1 Effect of change in symptom load of anxiety and

depression (follow-up minus baseline level) on blood pressure (follow-up minus baseline blood pressure) over 11 years.

(a) Systolic and (b) diastolic blood pressure (BP). Change above the 50th percentile indicates a relative increase, whereas change beneath the 50 th percentile indicates a relative decrease in symptom load from baseline to follow-up.

\section{Discussion}

We found that symptoms of anxiety and depression were associated with decrease in blood pressure. Both the increase in symptom load from baseline to follow-up and a high baseline symptom load predicted a decrease in blood pressure. These associations were found in both genders, were independent of baseline blood pressure, age and other risk factors usually associated with hypertension, and were not explained by the use of antidepressant or antihypertensive medication.

\section{Other studies}

Our findings are in contrast to earlier reports that suggested a link between anxiety and an increase in mean systolic but not diastolic blood pressure, ${ }^{5}$ and that neither anxiety ${ }^{4,6,7}$ nor depression ${ }^{3,7}$ had any effect on mean systolic and diastolic blood pressure. However, these studies had smaller sample sizes and were prone to selection biases; the only positive association (between anxiety at baseline and increase in systolic but not diastolic blood pressure) was found in a sample of 468 middle-aged women. ${ }^{5}$ Moreover, the results of ten studies employing blood pressure above a cut-off level or use of antihypertensive medication as outcomes are conflicting: four found that anxiety predicted hypertension ${ }^{15-18}$ and three that depression predicted hypertension, ${ }^{15,16,19}$ whereas four found no effect of anxiety ${ }^{4,6,7,20}$ and four found no effect of depression. ${ }^{6,7,20,21}$ Some of the positive associations have been found only in subsamples according to gender ${ }^{16}$ or ethnicity. ${ }^{18,19}$ A 2-year follow-up study in elderly people found that low blood pressure was a risk factor for, but not a consequence of, depression. ${ }^{22}$

In contrast, three cross-sectional studies among the elderly found an association between high anxiety and depression and low blood pressure, ${ }^{23-25}$ consistent with our previous report ${ }^{8}$ and with another large population-based study of young adults. $^{26}$

\section{Strengths and limitations}

Previously, only two studies of middle-aged women with small sample sizes ${ }^{5,6}$ have examined the effect of increasing anxiety or

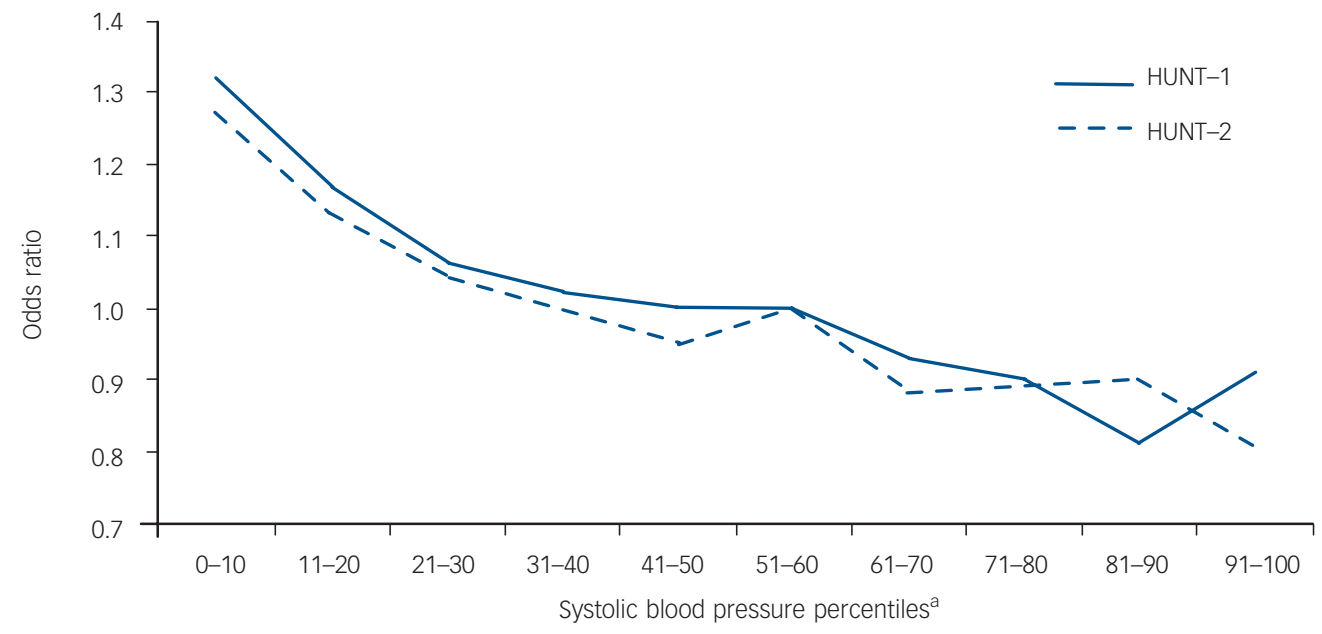

Fig. 2 Cross-sectional associations between systolic blood pressure and anxiety and depression in HUNT-1 and HUNT-2.

Odds ratio from logistic regression analyses, outcomes being scores above the 90th percentile of the Anxiety and Depression Symptom Index-12 in HUNT-1 ( $n=60143$ ) and the Hospital Anxiety and Depression Scale in HUNT-2 ( $n=60799)$, adjusted for age, gender and educational level. The 51-60th percentile systolic blood pressure was reference group. a. Stratified for age and gender. 
depression on change in blood pressure, based on measurements both at baseline and follow-up. In contrast, most longitudinal studies have only assessed the association of anxiety or depression at baseline and blood pressure measured from months to many years later. Our study analysing change in anxiety and depression in relation to change in blood pressure over a decade in a large population is methodologically more advanced than most other studies.

Another strength is that our study covered a large unselected adult population within a geographical area with a high participation rate. ${ }^{9,10}$ As blood pressure varies greatly with gender and age, the use of mean blood pressure and age- and gender-stratified percentiles is better for assessing change than traditional cut-off values. ${ }^{8}$ Furthermore, we had a long follow-up period and data on relevant covariates.

This study has some limitations. First, anxiety and depression were measured with different instruments at baseline and followup. Although the HADS at follow-up is a well-established screening instrument in epidemiology, ${ }^{14}$ the ADI-12 Index used at baseline is less established. However, several items of the two scales overlapped with high correlations between them and with comparable associations with age (data not shown). In addition, the ADI-12 Index has previously reported strong correlations with the Hopkins Symptoms Checklist-25. ${ }^{11}$ Of great interest is that the cross-sectional associations between blood pressure and anxiety and depression were almost identical at baseline and at follow-up (Fig. 2), indicating no major problems applying different psychometrics.

Second, different methods of measuring blood pressure were used at baseline and follow-up. However, as these two methods were found to give similar results, ${ }^{27}$ it is unlikely that this could influence the associations we have observed.

Third, because most of the participants were White, the extent to which the results can be generalised to other ethnic groups is uncertain.

\section{Possible mechanisms and future studies}

Our data do not elucidate the mechanism behind the findings. The cross-sectional ${ }^{8}$ and longitudinal analyses included many covariates, but they explained very little of the association. Similarly, the individual-item analyses did not reveal any pattern suggesting mechanisms for the association. There is, however, considerable evidence suggesting that symptoms of anxiety and depression are associated with alterations in the hypothalamicpituitary-adrenal system, ${ }^{28}$ and some indications of abnormal autonomic nervous function in depression. ${ }^{29}$ In the past two decades, numerous studies have suggested that neuropeptide Y, one of the most abundantly expressed neuropeptides, has important functions in these systems and exhibits effects in various domains such as food intake, blood pressure and mental symptoms. A recent review has shown that patients with depression have altered levels of neuropeptide $\mathrm{Y}$ and that cerebrospinal fluid levels of neuropeptide $\mathrm{Y}$ have been found to be inversely associated with anxiety scores in these patients. ${ }^{30}$ Another review highlights its anxiolytic and antidepressant-like effects. ${ }^{31}$ Regarding the cardiovascular system, neuropeptide $\mathrm{Y}$ in the brain seems to suppress sympathetic activity and decrease blood pressure, ${ }^{32}$ whereas in the peripheral nervous system it induces vasoconstriction, ${ }^{33}$ which may be of a transient nature. ${ }^{34}$ Although the effects of neuropeptide $\mathrm{Y}$ and related peptides on vascular regulation are only partly understood, ${ }^{32}$ it seems reasonable that they are involved both in the well-known acute stress-induced increase in blood pressure and in the long-term inverse association between anxiety and depression and blood pressure that we found. More work is needed to explore the differences between the relationship of ongoing $v$. acute psychological distress on blood pressure and the underlying biological pathways.

Bjørn Hildrum, MD, Department of Psychiatry, Namsos Hospital, Namsos, and Norwegian University of Science and Technology, Trondheim; Arnstein Mykletun MA, PhD, Research Centre for Health Promotion, Faculty of Psychology, University of Bergen, and Norwegian Institute of Public Health, Division of Mental Health, Oslo; Jostein Holmen, MD, PhD, HUNT Research Centre, Department of Public Health and General Practice, Norwegian University of Science and Technology, Verdal; Alv A. Dahl, MD, PhD, Department of Clinical Cancer Research, the Norwegian Radium Hospital, Rikshospitalet University Hospital, Oslo, and Faculty Division, The Norwegian Radiumhospital, University of Oslo, Norway

Correspondence: Dr Bjørn Hildrum, Department of Psychiatry, Namsos Hospital, N-7800 Namsos, Norway. Email: bjorn.hildrum@hnt.no

First received 11 Sep 2007, final revision 16 Feb 2008, accepted 21 Apr 2008

\section{Acknowledgements}

The HUNT study is a collaboration between the HUNT research centre at the Faculty of Medicine, Norwegian University of Science and Technology, the Norwegian Institute of Public Health, and the Nord-Trondelag County Council. B.H. has received grants from Mid-Norway Regional Health Trust, Jonn Nilsen's Legacy, and H. Lundbeck, Norway.

\section{References}

1 Geisböck F. Die Bedeutung der Blutdruckmessung für die Praxise [The importance of blood pressure measurement in clinical practice]. Dtsch Arch Klin Med 1905; 83: 363-409.

2 Moschcowitz E. Hypertension. Its significance, relation to arteriosclerosis and nephritis and etiology. Am J Med SCi 1919; 158: 668-84.

3 Goldberg EL, Comstock GW, Graves CG. Psychosocial factors and blood pressure. Psychol Med, 1980; 10: 243-55.

4 Sparrow D, Garvey AJ, Rosner B, Thomas He Jr. Factors in predicting blood pressure change. Circulation 1982; 65: 789-94.

5 Markovitz JH, Matthews KA, Wing RR, Kuller LH, Meilahn EN. Psychological, biological and health behavior predictors of blood pressure changes in middle-aged women. J Hypertens 1991; 9: 399-406.

6 Räikkönen K, Matthews KA, Kuller LH. Trajectory of psychological risk and incident hypertension in middle-aged women. Hypertension 2001; 38: 798-802.

7 Shinn EH, Poston WS, Kimball KT, St Jeor ST, Foreyt JP. Blood pressure and symptoms of depression and anxiety: a prospective study. Am J Hypertens 2001; 14: 660-4.

8 Hildrum B, Mykletun A, Stordal E, Bjelland I, Dahl AA, Holmen J. Association of low blood pressure with anxiety and depression: the Nord-Trøndelag Health Study. J Epidemiol Community Health 2007; 61: 53-8.

9 Holmen J, Midthjell K, Bjartveit K, Hjort PF, Lund-Larsen PG, Moum T, Næss S, Waaler T. The Nord-Trøndelag Health Survey 1984-86: Purpose, Background and Methods, Participation, Non-participation and Frequency Distribution. Report No 4. National Institute of Public Health, Norway, 1990.

10 Holmen J, Midthjell K, Krüger $\varnothing$, Langhammer A, Holmen TL, Bratberg GH, Vatten L, Lund-Larsen PG. The Nord-Trøndelag Health Study 1995-97 (HUNT 2): objectives, contents, methods and participation. Norsk Epidemiologi 2003; 13: $19-32$.

11 Tambs K, Moum T. Low genetic effect and age-specific family effect for symptoms of anxiety and depression in nuclear families, halfsibs and twins. J Affect Disord 1993; 27: 183-95.

12 World Health Organization. The ICD-10 Classification of Mental and Behavioural Disorders: Clinical Descriptions and Diagnostic Guidelines. WHO, 1992.

13 Mykletun A, Stordal E, Dahl AA. Hospital Anxiety and Depression (HAD) scale: factor structure, item analyses and internal consistency in a large population. Br J Psychiatry 2001; 179: 540-4.

14 Bjelland I, Dahl AA, Haug TT, Neckelmann D. The validity of the Hospital Anxiety and Depression Scale. An updated literature review. J Psychosom Res 2002; 52: 69-77.

15 Jonas BS, Franks $\mathrm{P}$, Ingram DD. Are symptoms of anxiety and depression risk factors for hypertension? Longitudinal evidence from the National Health and Nutrition Examination Survey I Epidemiologic Follow-up Study. Arch Fam Med 1997; 6: 43-9.

16 Jonas BS, Lando JF. Negative affect as a prospective risk factor for hypertension. Psychosom Med 2000; 62: 188-96. 
17 Markovitz JH, Matthews KA, Kannel WB, Cobb JL, D'Agostino RB. Psychological predictors of hypertension in the Framingham Study. Is there tension in hypertension? JAMA 1993; 270: 2439-43.

18 Somova LI, Connolly C, Diara K. Psychosocial predictors of hypertension in black and white Africans. J Hypertens 1995; 13: 193-9.

19 Davidson K, Jonas BS, Dixon KE, Markovitz JH. Do depression symptoms predict early hypertension incidence in young adults in the CARDIA study? Arch Intern Med 2000; 160: 1495-500.

20 Yan LL, Liu K, Matthews KA, Daviglus ML, Ferguson TF, Kiefe CI. Psychosocia factors and risk of hypertension: the Coronary Artery Risk Development in Young Adults (CARDIA) study. JAMA 2003; 290: 2138-48.

21 Levenstein S, Smith MW, Kaplan GA. Psychosocial predictors of hypertension in men and women. Arch Intern Med 2001; 161: 1341-6.

22 Paterniti S, Verdier-Taillefer MH, Geneste C, Bisserbe JC, Alpérovitch A. Low blood pressure and risk of depression in the elderly. A prospective community-based study. Br J Psychiatry 2000; 176: 464-7.

23 Barrett-Connor E, Palinkas LA. Low blood pressure and depression in older men: a population based study. BMJ 1994; 308: 446-9.

24 Stroup-Benham CA, Markides KS, Black SA, Goodwin JS. Relationship between low blood pressure and depressive symptomatology in older people. J Am Geriatr Soc 2000; 48: 250-5

25 Jorm AF. Association of hypotension with positive and negative affect and depressive symptoms in the elderly. Br J Psychiatry 2001; 178: 553-5.
26 Herva A, Räsänen $P$, Miettunen J, Timonen M, Läksy K, Veijola J, Laitinen J, Ruokonen A, Joukamaa M. Co-occurence of metabolic syndrome with depression and anxiety in young adults: the Northern Finland 1966 Birth Cohort Study. Psychosom Med 2006; 68: 213-6.

27 Lund-Larsen PG. Blood pressure measured with sphygmomanometer and with Dinamap under field conditions - a comparison. Norsk Epidemiologi 1997; 7: 235-41.

28 Ströhle A, Holsboer F. Stress responsive neurohormones in depression and anxiety. Pharmacopsychiatry 2003; 36 (suppl 3): s207-14.

29 Scalco AZ, Scalco MZ, Azul JB, Lotufo Neto F. Hypertension and depression. Clinics 2005; 60: 241-50.

30 Karl T, Herzog H. Behavioral profiling of NPY in aggression and neuropsychiatric diseases. Peptides 2007; 28: 326-33.

31 Carvajal C, Dumont Y, Quirion R. Neuropeptide Y: role in emotion and alcohol dependence. CNS Neurol Disord Drug Targets 2006; 5: 181-95.

32 Matsumura K, Tsuchihashi T, Fujii K, lida M. Neural regulation of blood pressure by leptin and the related peptides. Regul Pept 2003; 114: 79-86.

33 Pons J, Lee EW, Li L, Kitlinska J. Neuropeptide Y: multiple receptors and multiple roles in cardiovascular diseases. Curr Opin Investig Drugs 2004; 5 : 957-62.

34 Kellogg DL. In vivo mechanisms of cutaneous vasodilation and vasoconstriction in humans during thermoregulatory challenges. J Appl Physiol 2006; 100: 1709-18.

\section{Psychiatry in the old Testament}

\section{Alcoholism in ancient Israel}

\section{George Stein}

When president Yeltsin failed to get off the plane at Shannon airport on his state visit to Ireland it was generally assumed that he was drunk. However, he was certainly not the first world statesman to be drunk. Thus Noah, the saviour of all humankind and all animal species from the flood, was similarly afflicted. 'Noah a man of the soil was the first to plant a vineyard. He drank some of the wine and became drunk and he lay uncovered in his tent' (Gen 19: 20-21). In the northern kingdom of Israel, king Elah, the son of king Basha, who only had a very short reign from 883 to 882 B.C.E. may have lost his job because of drinking: 'When [Elah] was at Tirzah drinking himself drunk in the house of Arza ... Zimri came and struck him down and killed him in the 27th year of the reign of King Asa of Judah and succeeded him' (I Kings 15: 9-10).

The consumption of alcohol was probably widespread in the ancient world and Proverbs 23: 29-35 has an excellent description of many of its neuropsychiatric complications:

29 'Who has woe? Who has sorrow? Who has strife? Who has complaining? Who has wounds with no cause? Who has redness of eyes?

30 Those who linger late over wine when it is red, when it sparkles in the cup and goes down smoothly.

32 And the last it bites like a serpent and stings like an adder.

33 Your eye will see strange things and your mind utter perverse things.

34 You will be like one who lies down in the midst of the sea, like one who lies on top of the mast. "They struck me" you will say, "but I was not hurt, they beat me but I did not feel it".

35 When shall I awake? I will seek another drink.'

This brief passage alludes to alcohol-induced depression, irritability, redness of the eyes, visual hallucinations, dizziness, change of character, and addictiveness with morning drinking. Elsewhere in Proverbs there is a reference to alcoholic violence:

'20, 17 Wine is a mocker, strong drink a brawler' and also

4, 17 'For they eat the bread of wickedness and drink the wine of violence.' Alcoholism and alcoholic violence were well recognised in ancient Israel and must have been serious problems, just as they are in Britain today. 